\title{
New Technical and Normative Challenges for XBRL: Multidimensionality in the COREP Taxonomy ${ }^{1}$
}

\author{
Ignacio Boixo. XBRL Spain. \\ xbrl@bde.es
}

Francisco Flores. University of Huelva.

francisco.flores@alu.uhu.es

\begin{abstract}
The New Basel Capital Agreement, known as Basel II, requires some notable changes in the systems of measurement and control of risks of credit entities and investment firms. It introduces new concepts and requirements. The systems of risk management to which the Framework or Agreement makes reference can be implemented in various degrees of sophistication. By measuring the different exposures to risk with greater accuracy, a more advanced system offers such firms and entities the prospect of needing less own funds and using increased financial leverage over secure bases. The national Supervisors, in the various central banks, must approve the systems and instruments established. The new reporting tool that is destined to fulfil this function, for the moment in the context of the European Union only, is the COREP-XBRL Taxonomy. This is based on the mark-up language of the business world, the eXtensible Business Reporting Language, and makes use of the concept of Multidimensionality. This concept is being incorporated into the XBRL specification currently in force, since it is necessary for the structure of the new reporting model that is required.
\end{abstract}

Key words: Basel II, XBRL, CEBS, COREP, multidimensionality.

\footnotetext{
The initials COREP stand for Common Solvency Ratio Reporting Framework. The descriptions refer to the Taxonomy 0.5 version 2005-05-13, available on www.corep.info, and to its explanatory notes. They may undergo changes in the near future. The intellectual property, to the extent described, belongs to the Committee of European Banking Supervisors (CEBS). Equally, the principles on which the architecture of the taxonomy is based, from the point of view of users, can be found on the website of the CEBS http://www.c-ebs.org/Consultation papers CoverNoteCP04.htm). The present section comprises, in addition to these contents, the opinions and comments of the authors, for which they acknowledge full ownership and responsibility. Particularly, we would like to thank Enrique Bonsón, Francisco Javier Cobo, Ignacio Hernández-Ros, Magdalena Llano, Antonio Menchero, Pablo
} 


\section{INTRODUCTION}

The Solvency Ratio of $8 \%$, between admissible own funds and assets weighted by risk, is well known around the world in the field of banking supervision and the control of risks, This ratio was introduced by the Basel Capital Agreement of 1988 (henceforth Basel I).

Basel I, an Agreement of non prescriptive character, has over time been incorporated in the banking legislation and the recommended practices of almost all countries of the world. The reason is that, despite this Framework initially being intended for entities with a transnational profile, other entities have considered it appropriate to be used as a control measure.

The extension of the Solvency Ratio, among other measures proposed in Basel I, has contributed to improving financial stability, and has made possible a certain competitive comparability. Not without reason, capital is a key factor for a credit institution or an investment firm (Rowe et al., 2004).

The updating that the Basel Committee on Banking Supervision proposes with the New Agreement or Framework (Basel II), the text of which we find in a stable version in 2004, incorporates novel qualitative aspects. It substantially modifies the quantitative aspects. It gives relevance to practices and internal systems introduced in banking. It promotes greater coordination with the supervisory authorities, which have new powers and functions. And, finally, it allows a better appreciation of the level of risk to which entities find themselves exposed.

It is expected that the New Framework will be put into effect in the period 20062008. This introduction would not represent an increase in the needs for admissible own funds, but rather that these amounts should correspond more faithfully to risk

\footnotetext{
Navarro and Panagiotis Voulgaris for the clarifications given to the second of the authors on the structure of the taxonomy XBRL. Equally we wish to thank the members of the inaugural workshop of the COREP project for their help and their participation: Adrian Abbott, Alejandro Sanz, Aliki Kazakopoulo, Annica Lundblad, Antonio Menchero, Antonio Sánchez-Serrano, Arturo Labanda, Bryce Pippert, César Pérez-Chirinos, Charles Hoffman, Cormac McKenna, Cristina Mena, Daniel D’Amico, Daniel Hamm, David Castro, Delphine Moreau, Dennis Pels, Don Inscoe, Emilio Querol, Fernando Navarrete, Fernando Wagener, Francesco Canfora, Francisco Flores, Frédéric Marie, Gustavo Garcia, Ignacio Boixo, Ignacio Hernández-Ros, J. Emilio Labra, Javier Cobo, Javier de Andres, Jean-Marie Coudière, Jesus F. Liger, Johan Giertz, José Luis F. Cuñado, Josef Macdonald, Katrin Schmehl, Klaus Baumann, Krisztina Tamási, Magdalena Llano, Michele Romanelli, Olivier Servais, Pablo Navarro, Pamela Maggiori, Panagiotis Voulgaris, Paolo Milani , Pedro Lorca, Phil Walenga, Ron Baremans, Victoria Santillana, Walter Hamscher and many other members of the group in whose company the authors had the pleasure of spending many interesting hours.
} 
exposures correctly detected and measured. In addition, it is required that entities cover important figures like those encompassed by the term Operational Risk, which must be dealt with explicitly (Embrechts et al., 2003). This risk was not considered in the previous Framework. We can be sure then that the New Framework is more ambitious than its predecessor (Cronin and Jaggs, 2001).

Basel II is structured on three Pillars:

\section{$\checkmark \quad$ Pillar I: Capital Requirements}

This first main grouping deals with the Risks that a banking entity or investment firm must take into account when its Capital Requirements are determined. In other words, it concerns the amount of admissible own funds that should figure in its balance sheet in function of the structure presented by its portfolio of assets, and the security offered to its clients, and its internal management processes. Measures to be taken in respect of the Credit Risk, Market Risk and Operational Risk are established. The methods for obtaining the required amount of admissible own funds that correspond to each area of risk are indicated. For each Risk different Methods for this exist, some Standard and/or Basic and others Advanced and/or Internal, together with the mechanisms for transitions between the different methods.

\section{$\checkmark$ Pillar II: Supervisory Examination Process}

In this grouping, the role that the supervisory authorities should play is defined. They must validate or approve of relevant processes, techniques and practices. In a context in which the internal systems established by these entities become protagonists, the function of the supervisory authority becomes essential. One priority for the supervisory authority is the protection of depositors (Pezier, 2002).

\section{$\checkmark \quad$ Pillar III: Market Discipline}

Requirements for the dissemination of information are established, as a consequence of the processes of management, measurement and validation of the systems for administering the various different risks. Increased transparency is enforced, now particularly in relation to the management of risks (Rowe et al., 2004). 
In the context of the European Union, the New Framework comes into effect with nuances in respect of community juridical regulation through the reform and consolidation of two important Directives, 2000/12 CE, and 93/6 CEE. At the time of writing, this adaptation is at the stage of awaiting approval by the European Parliament.

The philosophy is simple: the creation of a Single European Financial Market requires an adequate framework of behaviour, and some useful and pertinent practices in the area of risk for financial entities. In addition, it must be ensured that competition functions correctly, and that appropriate corrections are applied for smaller sized entities.

The new normative frameworks require the consideration of these different types of risk when the Minimum Capital Requirements of Pillar I are determined:

a) Credit risk: which is incurred as a consequence of the credit-issuing activity undertaken.

b) Market risk: which is derived from the entity's positions in the various different market places, and by the holding of other assets.

c) Operational risk: to which an entity is exposed arising from technical, human, and administrative failures or faults, as well as possible frauds that entities may suffer.

Although each risk must be managed specifically, the integration of risks is also applicable (Mendova and Kyriacou, 2001). And the interrelationships between the management of risks and the general management needs careful handling, considering that an excessively-fragmented organisation is not only unlikely to measure its risks well but would be more likely to promote, indirectly, increased operational losses (Pezier, 2002).

In both Basel II and the reformed Directives, various options are available to entities as regards the degree of sophistication and sensitivity of their systems for the management of risks (standard method, method of internal qualifications, ...)

The use of more advanced methods and systems in principle represents an effort towards adaptation and improvement which involves higher costs. However, 
there are two powerful reasons for moving towards the application of these more advanced methods in place of the standard methods (See Fig. 1):

a) The banks and investment entities can adapt to take full advantage of the internal systems of assessment and measurement that were already utilising, with the requirement that they should be validated by the supervisory authority.

b) The use of a more sophisticated system of risk measurement may permit a reduction of the capital requirements they must maintain. This would increase their capacity for financial leverage on a secure base, and increase the competitive capacity and the investment capacity of the entity.

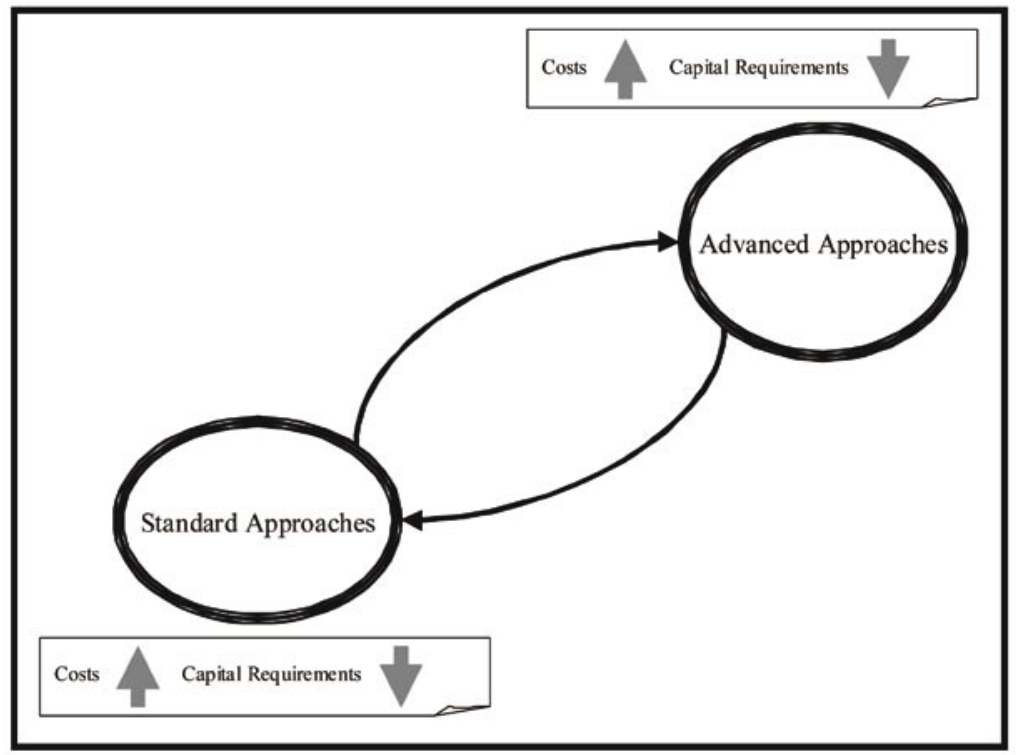

Figure 1. Interrelationship Between Degrees of Sophistication in the Methods of Measurement.

Therefore the correct implementation of the New Framework does not aim to produce an increase in the amount of admissible own funds, but rather a slight decrease in overall terms. However, at the level of the entity, that decrease in the own funds needed may be larger or smaller depending on the degree of sophistication of the methods employed. It demonstrates that you need to manage risks better than your competitor (Rowe et al., 2004). 
Therefore, the choice of the method of measurement, among those proposed by the New Framework, is especially important. In addition, the incentives that we are speaking of can facilitate the entity's relationship with the supervisory authority (Cronin and Jaggs, 2001).

The degree of difficulty in adapting depends directly on the starting situation. Thus, there will be entities that are currently equipped with complete internal systems of risk measurement. Additionally, these entities would have been monitoring the new necessities that were going to arise with the entry into force of the New Framework, which began to be drawn up back in 1998. As a result, they will have to make changes of detail in their policies and management techniques to obtain the validation of the supervisory authorities. A degree of flexibility will be open to entities when it comes to establishing particular methods of sophisticated measurement, such as the AMA (Advanced Measurement Approach). The more advanced methods will tend to be preferred by entities of larger size (Embrechts et al., 2003).

Now, this process of adaptation to the new rules of the game will involve, in our opinion, an undeniable technical and human effort, particularly on the following points:

a) Internal auditing and control: to adapt the systems of control over the Operational Risk. The circumstance has arisen that, for the first time, these issues can generate significant Capital Requirements and not only extraordinary losses.

b) Coordination with the supervisory authority, which plays a fundamental role in the validation of many of the components of the systems set up or to be set up.

In these circumstances, information and communications technologies should play a front-line role, enabling the transmission, management and recording of the various types of information generated to be rapid and reliable. Above all, considering that the implementation of the new regulation involves compliance with a new model of reporting information required by the Supervisor: the COREP templates. 
As we shall see, the incentive exists, especially in the light of the management advantages provided by XBRL, as pointed out by the Committee of European Banking Supervisors (CEBS) itself. We can state, for example, that XBRL is currently serving as a powerful tool for internal and external auditors when checking their clients' compliance with the U.S. Sarbanes-Oxley Law of 2002 (Coderre, 2004).

In Europe, the New Basel Capital Agreement appears in the form of the reformed EU Directives 2000/12 and 93/6. In accordance with the European legislative system, these Directives, in turn, have to be transposed into the national legislation of each and every one of the 25 states that now comprise the European Union. Each of these 25 pieces of national legislation has to be developed as a regulatory ruling by the competent supervisory body in each state. In accordance with the national criteria and characteristics, each Supervisor can request a greater or less degree of aggregation or break-down from the entities it supervises in the new system of COREP reporting, and can demand or dispense with any specific piece of information. (See Fig. 2).

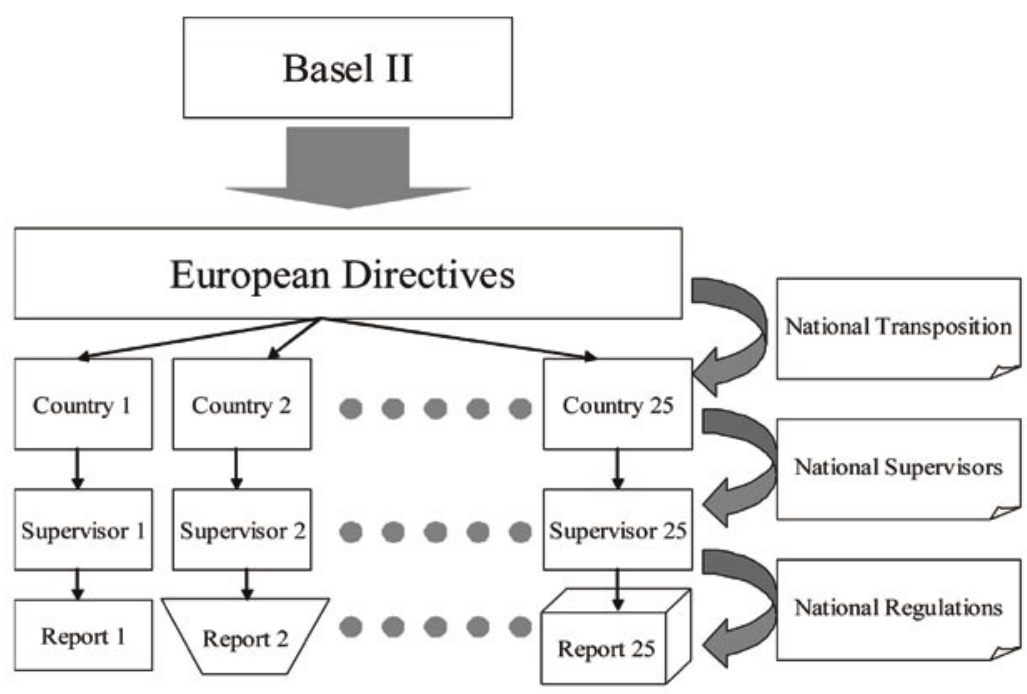

Figure 2. The Process of Adaptation from Basel II to the National Reports of Risk.

To face the challenge of maintaining the practical application of Basel II in harmony across all states, while at the same time adapting it to the particular 
characteristics of each individual State, a solution is required that is sufficiently robust to maintain its coherence yet sufficiently flexible to allow for a diversity of approaches to its application.

The eXtensible Business Reporting Language XBRL has been designed precisely to meet these objectives, and for this reason has been chosen to support the new model of reporting. This will make communication between the entities and the supervisors possible: the COREP templates, which take material form in the COREP-XBRL Taxonomy.

XBRL has important implications for financial reporting, and one notable feature we would stress is its capacity for allowing the use of the user's software to search for and present information (Hodge, Kennedy and Maines, 2004).

The flexibility of XBRL clearly exists because, once the taxonomy of international applicability has been completed, each Supervisor can adapt (and extend) this inventory of information to its own particular regulations, either broadening it, or narrowing it, or just modifying some of its characteristics. Effectively, each supervisor is creating its own extension from the international taxonomy.

The economics of XBRL (See Fig. 3) are clear because the technological infrastructure is separated from the business rules. All the XBRL programming and software required are normalised, and are independent of the specific forms of utilisation: the changes that may occur in the business rules will not affect the technological infrastructure of XBRL. All the information referring to the business rules is defined in XBRL taxonomies, which are published on the Internet so that they can be read immediately by anyone and from anywhere in the world, at no cost, and these taxonomies are modifiable by the Supervisor to cover or adapt to the regulatory necessities that may periodically arise. The taxonomy serves as a kind of "dictionary" of XBRL elements (XBRL web site, 2005). 


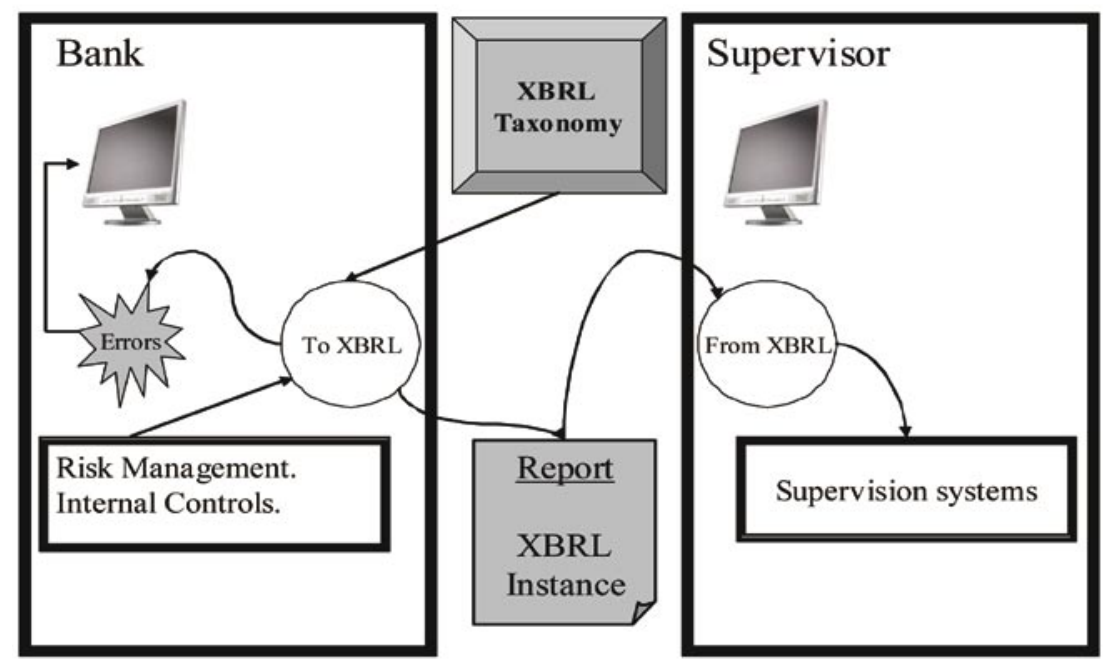

Figure 3. Flow of Data. XBRL Validates Errors and Inconsistencies in the Issuer of Information. The Regulatory Changes are Implemented with a Change in the Reference Ttaxonomy.

Just as the Supervisor publishes in conventional language the regulation to be observed or complied with by the entities supervised, it can also publish certain parts of the same regulation in XBRL, to be observed and complied with by the information technology infrastructure, I.e. the computer systems, that utilise the XBRL standard. We have what the regulation indicates in the standardised approach: credit risk mitigation techniques that have to comply with the premise: exposure net of value adjustments and provisions = original credit $\&$ counterparty risk exposure pre credit conversion factor - value adjustments and provisions associated with the original exposure.

This rule can also be expressed by the Supervisor in the XBRL language, in such a way that the XBRL infrastructure will validate that this relationship is complied with in each XBRL report where it may be applicable. Material errors of this kind are going to be detected directly by the entity Supervised, in the course of preparing its XBRL report.

From the point of view of the entity Supervised, one of the biggest advantages is this immediacy in the detection of errors, inconsistencies and regulatory noncompliances. As the supervisor publishes on the Internet the regulation to be followed (XBRL taxonomy), the XBRL infrastructure can validate automatically 
that the reports that it generates are in accordance with the regulation in force. The standard XBRL software checks that every report generated meets each and all of the specifications and business cautions that the Supervisor may have regulated. Any error or discrepancy is immediately detected within the system of information of the Supervised entity (Fig. 4), and can be corrected before that report is sent to the Supervisory body. Since the business rules appear exclusively in the taxonomy published on the Internet by the Supervisor, the programs to be utilised in the XBRL validation are a stable standard, and should not undergo any variations because the regulations may vary.

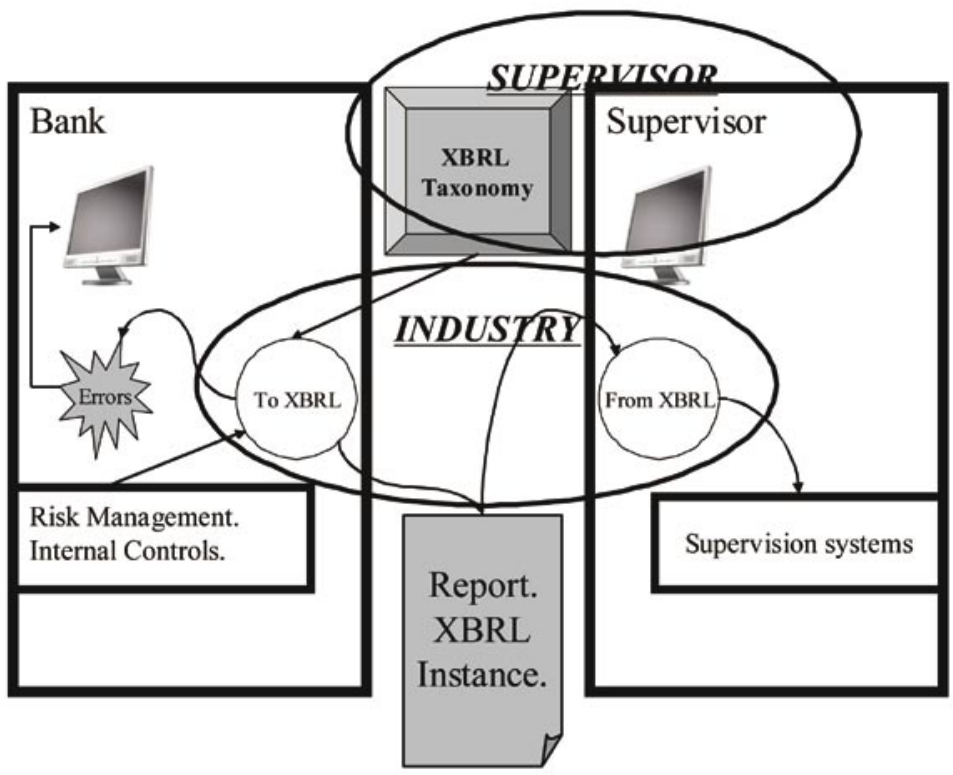

Figure 4. The Supervisors Handle Taxonomies. The Industry Handles Components.

Turning our attention to typologies of the entities supervised and the national supervisors, at the present time different situations are found:

a) Advanced or multinational bank: it reports by means of XBRL to the different supervisors of each country, in the various countries in which it operates. Its information is structured following the XBRL format. When several supervisors request it to provide reports in XBRL, a bank of this type obtains an immediate saving, since it can meet its obligations to the various national Supervisors by sending the information required in the 
same format, thus processing the data only once, with no need to carry out any specific work for each supervisor. (Fig. 5).

b) Banks with their own converter: They simply need to manage their risks in accordance with their internal information system. The software suppliers provide the appropriate converters so that the relevant aggregates are transformed into information in XBRL format, ready to be sent to the supervisor. (Fig. 5).

c) Banks with external solution: It could be the case that the information required can simply be keyed into a spreadsheet or a Web page and then, once accepted, a set computer procedure would generate the XBRL report to be sent to the supervisor. This automatic generation can be done without any technological obstacles even by an applications service supplier (ASP) who may perform this function as a service for a number of different bank, thus obtaining economies of scale.(Fig. 5).

d) Supervisors in the initial stages: They simply need a converter that transforms the XBRL reports into files that can be assimilated by their own information system. The XBRL converter is a standard product, and is independent of whichever entity has generated the XBRL report. From the point of view of the supervisor, it is irrelevant that the report may have been generated by a small bank local, with basic technology or by a large multinational bank, or even generated and sent from a data processing centre in another country, since the XBRL format is standard, and the information from all sources will reach the supervisor in the same way.(Fig. 6).

e) Supervisor with advanced systems: In addition to receiving XBRL reports corresponding to obligations under the New Basel Capital Agreement, such supervisors can process others reports that arrive in the XBRL format, which may be based on applications of the International Accounting Standards (IFRS), or on other relevant information specifications.(Fig. $6)$.

f) Exchange between supervisors: when they receive the information in a normalised format, supervisors can share important information more easily. The XBRL reports are directly legible when passed from one 
supervisor to another, since they are internationally normalised and have their labels defined in different languages, and all their characteristics of accounting detail and legal references have been specified. (Fig. 6).

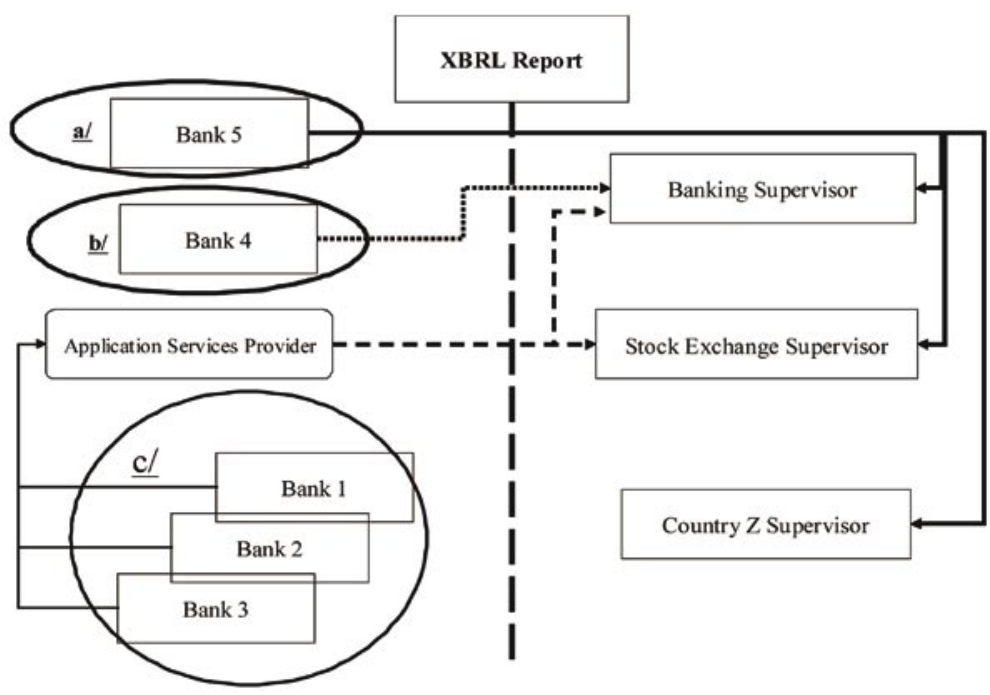

Figure 5. Typology of Banks, Before Adaptation to the New Model for Reporting Risks.

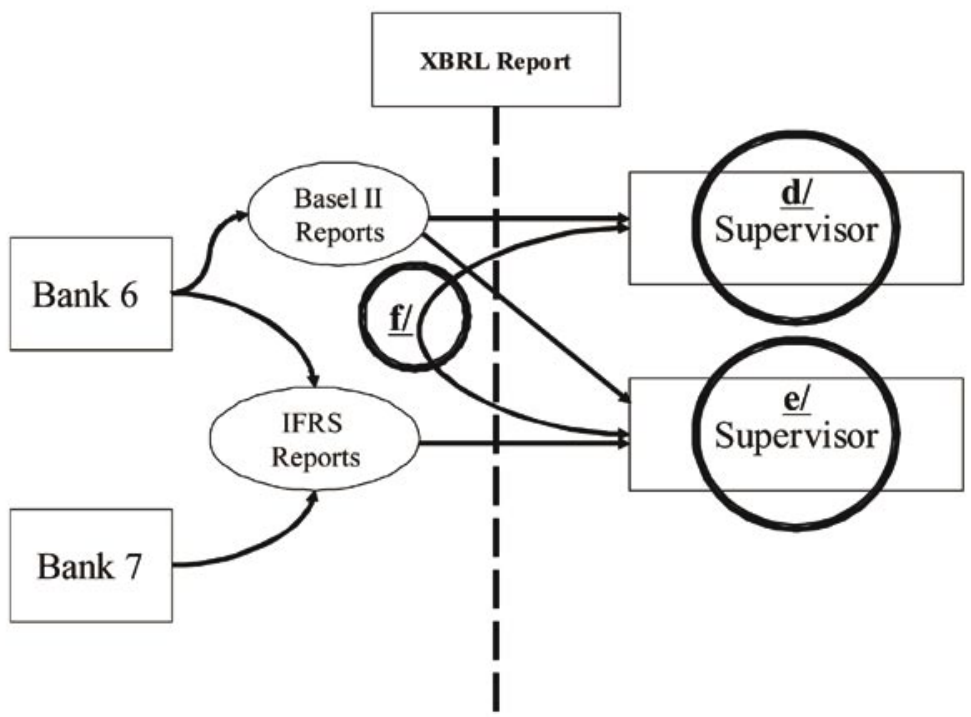

Figure 6: Typology of Supervisors, Before Adaptation to the New Model for Reporting Risks. 
The situation in the European Union is one of a harmonised market offering good economies of scale. Since the formats and definitions of the required data in respect of the New Basel Capital Agreement have been agreed internationally, harmonisation on the full detail can be guaranteed. Differences of interpretation, national traditions or other divergences have to be explained in such a way that it is made evident what of common scope and what are developments of national scope, without any confusion between the two arising. Hence the use of XBRL in Europe serves to homogenise business information and contributes to the development of the European Financial Market (Bonsón, 2001).

The credit entities will prepare their supervision reports utilising exactly the same definitions and the same standards, which should represent a considerable saving of cost and time. These reports, in turn, can be adapted to the particular national requirements without the need to start again with technological development work, but rather just simply adapting the information systems to the specific requests of the regulators.

The credit entities have the guarantee that the framework is equal for all, where local peculiarities are not going affect, inappropriately, the competitivity of some entities against others.

The supervisors will be able to compare among themselves the previously harmonised ratios, and within the common reports, to request at any time the break-down of any aggregated data that they may require, or to reduce the level of disaggregation if they want a less detailed picture of the entity under their supervision.

With respect to Pillar III, concerning Market Discipline, the XBRL language can make a great contribution. The credit entities can publish in XBRL their balance sheets and relevant financial information, so that the market may have at its immediate disposal information that, since it is normalised, can be directly processed, very fast and free from errors. Since this information comes from the same source, and is obtained by the same procedures, as the information declared to the Supervisor, its fidelity and reliability are guaranteed. The delays while it is being transcribed, the inconvenience of a diversity of formats, the inconsistencies in the interpretation, the lack of comprehension between national languages, and the material keyboard errors disappear immediately. An efficient market owes 
much to symmetry in information availability, both in time and in the extent of its dissemination. Financial information has to be processed rapidly and efficaciously for it to be able to contribute to the Market Discipline reflected in Pillar III. Financial information published in XBRL meets this requirement.

\section{COREP-XBRL TAXONOMY}

As can be seen, we can establish a double challenge for XBRL in respect of the incorporation of the New Basel Capital Agreement into the European financial system. First, there is the need to respond to the hierarchical diagram of adaptations proposed in Figure 2. As we have seen, this problem is resolved by the properties inherent in the whole XBRL taxonomy. And second, there is the challenge of multidimensionality in the COREP templates.

The COREP templates make use of a model of representation of the data associated with the different risks (losses, investments, accounting adjustments made, ...) by means of a peculiar distribution. Each datum is represented by a set of coordinates formed by a single measure and one or several dimensions.

In the description of the taxonomy, we find the following definitions:

$\checkmark$ Dimension: Scenarios in whose contexts data are being reported, for example: exposure class, exposure type

Measure: Data points being reported, for example: exposure value, exposure weighted average LGD, expected loss.

$\checkmark$ Template: Created from the combinations of dimensions and measures being reported, for example: CA (capital adequacy summary), SA (capital requirements), etc.

Thus the distinction between a measure and a dimension reside in the following: whereas the measure is an aspect to be dealt with, a relevant matter for the analysis of risk, the dimension is a break-down, a specialisation and/or a disaggregation of the data that provides the most appropriate picture of the reality of the risk situation to which the entity is exposed. In other words, the measures are variables to monitor, and the dimensions are the subclasses to which the different values taken by the variables belong. 
By way of illustration, in Chart 1 we show the measures in the COREP templates, which are the following:

\begin{tabular}{|c|c|c|}
\hline \multicolumn{3}{|c|}{ Measures } \\
\hline 1 & Capital Adequacy Summary & $m-c a$ \\
\hline 3 & Standardised Approach Capital Requirements & $m-s c$ \\
\hline 5 & Securitisation Exposures SA Synthetic Securitisations & $m-s 2$ \\
\hline 6 & IRB Approach Capital Requirements & m- ic \\
\hline 7 & Capital Requirements Specialized Lending Slotting Criteria & $m-c s$ \\
\hline 8 & Equity: PD/LGD Approach & $\mathrm{m}-\mathrm{el}$ \\
\hline 11 & Securitisation Exposures IRB Approach Traditional Securitisations & $m-i 1$ \\
\hline 12 & Securitisation Exposures IRB Approach Traditional Securitisations & $m-12$ \\
\hline 13 & SA: Details of Exposure Value And CRM & $\mathrm{m}-\mathrm{cr}$ \\
\hline 14 & FIRB Approach: Details of Exposure Value and CRM & $m-f c$ \\
\hline 15 & AIRB Approach and Retail: Details of Exposure Value and CRM & $m-a c$ \\
\hline 16 & CRM Providers of the Outflows Associated with CRM Techniques & $m-\pi$ \\
\hline 21 & Operational Risk Gross Losses in the Last Year & $m-$ ol \\
\hline 22 & Other Information on Major Counterparty Exposures & $m=01$ \\
\hline 23 & Other Information on Sectorial Exposures & $m-02$ \\
\hline 24 & Other Information on Affiliates & $m-$ oi \\
\hline 25 & Other Information on Major Operational Risk Gross Losses & $m-o m$ \\
\hline 26 & Other Information on Securitisation Details & $m-s d$ \\
\hline 27 & Summarized Information on Exposures & $m-d c$ \\
\hline 28 & Market Risk Standardised Approaches for Traded Debt Instruments & $m-t d$ \\
\hline 29 & Market Risk Standardised Approaches for Equities & $m-e b$ \\
\hline 30 & MKR SA FX & $m=p r$ \\
\hline 31 & Market Risk Standardised Approaches for Commodities & $m-p c$ \\
\hline 32 & Market Risk for Unsettled Transactions in the Trading Book & $m-u t$ \\
\hline
\end{tabular}

Chart 1. Measures.

These measures can be reported on one or several dimensions. These can be seen in Chart 2:

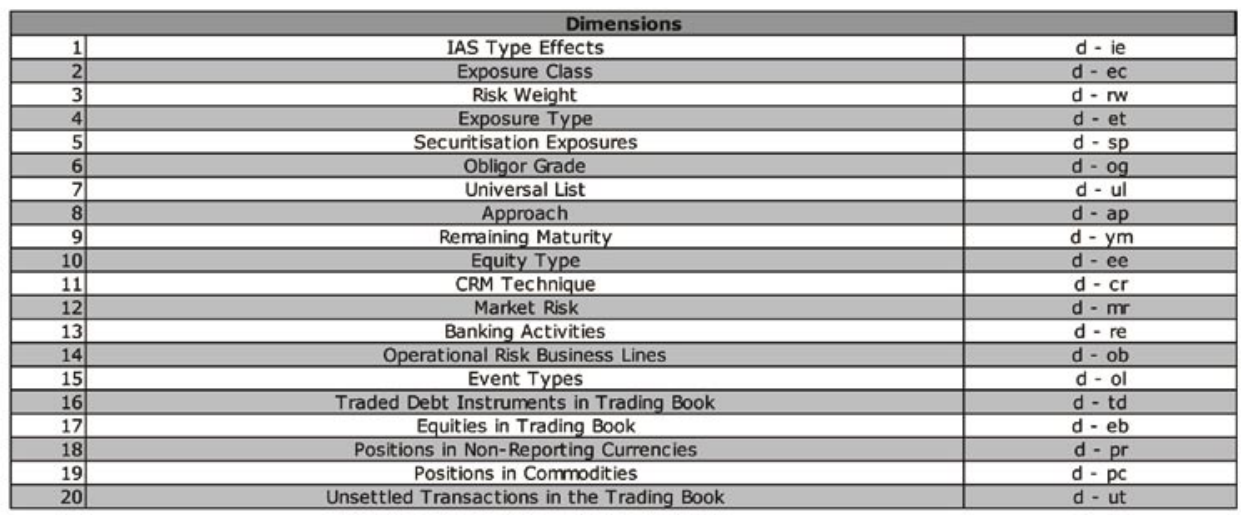

Chart 2. Dimensions.

As a result of the permitted and not permitted combinations, the COREP templates are generated. We can see in Chart 3 which are the permitted relationships, and the resulting templates: 


\begin{tabular}{|c|c|c|}
\hline Template & Measures Imported & Dimensions Imported \\
\hline $\begin{array}{l}\text { Name: } \mathrm{CA} \\
\text { Prefix: t-ca }\end{array}$ & $\begin{array}{l}\text { Name: Capital Adequacy Summary } \\
\text { Prefix: m-ca }\end{array}$ & No dimensions \\
\hline $\begin{array}{l}\text { Name: CA IAS } \\
\text { Prefix: } t-c i\end{array}$ & $\begin{array}{l}\text { Name: IAS Adjustments } \\
\text { Prefix: m-ci }\end{array}$ & $\begin{array}{l}\text { Name: IAS Type Effects } \\
\text { Prefix: d-ie }\end{array}$ \\
\hline $\begin{array}{l}\text { Name: SA } \\
\text { Prefix: t-sa }\end{array}$ & $\begin{array}{l}\text { Name: Standardised Approach Capital Requirements } \\
\text { Prefix: } \mathrm{m} \text {-sc }\end{array}$ & $\begin{array}{l}\text { Name: Exposure Class } \\
\text { Prefix: d-ec } \\
\text { Name: Risk Weight } \\
\text { Prefix: d-rw } \\
\text { Name: Exposure Type } \\
\text { Prefix: d-et }\end{array}$ \\
\hline $\begin{array}{l}\text { Name: SA SEC } 1 \\
\text { Prefix: t-s1 }\end{array}$ & $\begin{array}{l}\text { Name: Securitisation Exposures SA Traditional } \\
\text { Securitisations } \\
\text { Prefix: } \mathrm{m}-\mathrm{s} 1\end{array}$ & $\begin{array}{l}\text { Name: Securitisation } \\
\text { Exposures } \\
\text { Prefix: } \text { d-sp }\end{array}$ \\
\hline $\begin{array}{l}\text { Name: SA SEC } 2 \\
\text { Prefix: } t-s 2\end{array}$ & $\begin{array}{l}\text { Name: Securitisation Exposures SA Synthetic } \\
\text { Securitisations } \\
\text { Prefix: } \mathrm{m}-\mathrm{s} 2 \\
\end{array}$ & $\begin{array}{l}\text { Name: Securitisation } \\
\text { Exposures } \\
\text { Prefix: } \text { d-sp }\end{array}$ \\
\hline $\begin{array}{l}\text { Name: IRB: } \\
\text { Capital } \\
\text { Requirements } \\
\text { Prefix: t-ic }\end{array}$ & $\begin{array}{l}\text { Name: IRB Approach Capital Requirements } \\
\text { Prefix: } m \text {-ic }\end{array}$ & $\begin{array}{l}\text { Name: Obligator Grade } \\
\text { Prefix: d-og } \\
\text { Name: Exposure Type } \\
\text { Prefix: d-et } \\
\text { Name: Approaches } \\
\text { Prefix: d-ap } \\
\text { Name: Exposure Class } \\
\text { Prefix: d-ec }\end{array}$ \\
\hline $\begin{array}{l}\text { Name: IRB Slott } \\
\text { Prefix: } t \text {-is }\end{array}$ & $\begin{array}{l}\text { Name: Capital Requirements Specialized Lending } \\
\text { Slotting Criteria } \\
\text { Prefix: m-cs }\end{array}$ & $\begin{array}{l}\text { Name: Risk Weight } \\
\text { Prefix: d-rw } \\
\text { Name: Remaining Maturity } \\
\text { Prefix: d-ym }\end{array}$ \\
\hline $\begin{array}{l}\text { Name: IRB } \\
\text { EQU } 1 \\
\text { Prefix: t-e1 }\end{array}$ & $\begin{array}{l}\text { Name: Equity: PD/LGD Approach } \\
\text { Prefix: m-el }\end{array}$ & $\begin{array}{l}\text { Name: Equity Type } \\
\text { Prefix: d-ee } \\
\text { Name: Obligor Grade } \\
\text { Prefix: d-og }\end{array}$ \\
\hline $\begin{array}{l}\text { Name: IRB } \\
\text { EQU } 2 \\
\text { Prefix: t-e2 }\end{array}$ & $\begin{array}{l}\text { Name: Equity: Simple Risk Weight Approach Prefix: } \\
\text { m-cw }\end{array}$ & $\begin{array}{l}\text { Name: Risk Weight } \\
\text { Prefix: d-rw }\end{array}$ \\
\hline $\begin{array}{l}\text { Name: IRB } \\
\text { EQU } 3 \\
\text { Prefix: t-e3 }\end{array}$ & $\begin{array}{l}\text { Name: Equity Internal Models Approach } \\
\text { Prefix: m-ei }\end{array}$ & No dimensions \\
\hline $\begin{array}{l}\text { Name: IRB } \\
\text { SEC 1 } \\
\text { Prefix: t-i1 }\end{array}$ & $\begin{array}{l}\text { Name: Securitisation Exposures IRB Approach } \\
\text { Traditional Securitisations Prefix: } \mathrm{m}-\mathrm{i} 1\end{array}$ & $\begin{array}{l}\text { Name: Securitisation } \\
\text { Exposures } \\
\text { Prefix: d-sp }\end{array}$ \\
\hline $\begin{array}{l}\text { Name: IRB } \\
\text { SEC } 2 \\
\text { Prefix: } t-i 2\end{array}$ & $\begin{array}{l}\text { Name: Securitisation Exposures IRB Approach } \\
\text { Traditional Securitisations } \\
\text { Prefix: } \mathrm{m} \text {-i2 }\end{array}$ & $\begin{array}{l}\text { Name: Securitisation } \\
\text { Exposures } \\
\text { Prefix: } \text { d-sp } \\
\end{array}$ \\
\hline $\begin{array}{l}\text { Name: SA CRM } \\
\text { Prefix: } t-c r\end{array}$ & $\begin{array}{l}\text { Name: Standardised Approach: Details Of Exposure } \\
\text { Value And Credit Risk Mitigation Techniques } \\
\text { Prefix: } \mathrm{m}-\mathrm{cr}\end{array}$ & $\begin{array}{l}\text { Name: Exposure Type } \\
\text { Prefix: d-et } \\
\text { Name: Exposure Class } \\
\text { Prefix: d-ec }\end{array}$ \\
\hline $\begin{array}{l}\text { Name: FIRB } \\
\text { CRM } \\
\text { Prefix: } t-f c\end{array}$ & $\begin{array}{l}\text { Name: Foundation and Equity IRB Approach: Details of } \\
\text { Exposure Value and Credit Risk Mitigation Techniques } \\
\text { Prefix: } \mathrm{m}-\mathrm{fc}\end{array}$ & $\begin{array}{l}\text { Name: Exposure Type } \\
\text { Prefix: d-et } \\
\text { Name: Exposure Class } \\
\text { Prefix: d-ec }\end{array}$ \\
\hline
\end{tabular}

Chart 3. Permitted Relationships. 


\begin{tabular}{|c|c|c|}
\hline $\begin{array}{l}\text { Name: AIRB } \\
\text { CRM } \\
\text { Prefix: } t-a c\end{array}$ & $\begin{array}{l}\text { Name: Advanced IRB Approach and Retail: Details of } \\
\text { Exposure Value and Credit Risk Mitigation Techniques } \\
\text { Prefix: } m-a c\end{array}$ & $\begin{array}{l}\text { Name: Exposure Type } \\
\text { Prefix: d-et } \\
\text { Name: Exposure Class } \\
\text { Prefix: d-ec }\end{array}$ \\
\hline $\begin{array}{l}\text { Name: CRM I-O } \\
\text { Prefix: t-io }\end{array}$ & $\begin{array}{l}\text { Name: Breakdown by CRM Providers of the } \\
\text { Outflows Associated with CRM Techniques Having a } \\
\text { Redistribution Effect on the Exposure Value } \\
\text { Prefix: m-rr }\end{array}$ & $\begin{array}{l}\text { Name: Exposure Class } \\
\text { Prefix: d-ec } \\
\text { Name: Approaches } \\
\text { Prefix: d-ap } \\
\text { Name: CRM Technique } \\
\text { Prefix: d-cr }\end{array}$ \\
\hline $\begin{array}{l}\text { Name: MKR IM } \\
\text { Prefix: t-mi }\end{array}$ & $\begin{array}{l}\text { Name: Internal Models Overview } \\
\text { Prefix: m-io }\end{array}$ & $\begin{array}{l}\text { Name: Market Risk Factors } \\
\text { Prefix: d-mr }\end{array}$ \\
\hline $\begin{array}{l}\text { Name: MKR IM } \\
\text { Daily Basic } \\
\text { Prefix: } t-d b\end{array}$ & $\begin{array}{l}\text { Name: Market Risk Additional Information } \\
\text { Prefix: m-ai }\end{array}$ & $\begin{array}{l}\text { Name: Universal List } \\
\text { Prefix: d-ul }\end{array}$ \\
\hline $\begin{array}{l}\text { Name: MKR IM } \\
\text { Daily Day } \\
\text { Prefix: t-dd }\end{array}$ & $\begin{array}{l}\text { Name: Market Risk Daily Day Information } \\
\text { Prefix: m-di }\end{array}$ & $\begin{array}{l}\text { Name: Universal List } \\
\text { Prefix: d-ul }\end{array}$ \\
\hline $\begin{array}{l}\text { Name: OPR } \\
\text { Prefix: } t-o p\end{array}$ & $\begin{array}{l}\text { Name: Operational Risk: Basic Indicator, Standard, } \\
\text { Standard Alternative and Advanced Measurement } \\
\text { Approaches } \\
\text { Prefix: } \text { m-re }\end{array}$ & $\begin{array}{l}\text { Name: Banking Activities } \\
\text { Prefix: d-re }\end{array}$ \\
\hline $\begin{array}{l}\text { Name: OPR } \\
\text { LOSS } \\
\text { Prefix: } t-o l\end{array}$ & $\begin{array}{l}\text { Name: Operational Risk Gross Losses in the Last Year } \\
\text { Prefix: m-ol }\end{array}$ & $\begin{array}{l}\text { Name: Operational Risk } \\
\text { Business Lines } \\
\text { Prefix: d-ob } \\
\text { Name: Event Types } \\
\text { Prefix: d-ol }\end{array}$ \\
\hline $\begin{array}{l}\text { Name: OTH } 1 \\
\text { IND } \\
\text { Prefix: t-o1 }\end{array}$ & $\begin{array}{l}\text { Name: Other Information on Major Counterparty } \\
\text { Exposures } \\
\text { Prefix: } \text { m-o1 }\end{array}$ & $\begin{array}{l}\text { Name: Universal List } \\
\text { Prefix: d-ul }\end{array}$ \\
\hline $\begin{array}{l}\text { Name: OTH } 2 \\
\text { SECT } \\
\text { Prefix: t-o2 }\end{array}$ & $\begin{array}{l}\text { Name: Other Information on Sectorial Exposures } \\
\text { Prefix: } \mathrm{m}-\mathrm{o} 2 \\
\text { Name: Summarized Information on Exposures } \\
\text { Prefix: } \mathrm{m} \text { - dc }\end{array}$ & $\begin{array}{l}\text { Name: Universal List } \\
\text { Prefix: d-ul }\end{array}$ \\
\hline $\begin{array}{l}\text { Name: OTH } 3 \\
\text { AFF } \\
\text { Prefix: } t-03\end{array}$ & $\begin{array}{l}\text { Name: Other Information on Affiliates } \\
\text { Prefix: m-oi }\end{array}$ & $\begin{array}{l}\text { Name: Universal List } \\
\text { Prefix: d-ul }\end{array}$ \\
\hline $\begin{array}{l}\text { Name: OTH } 4 \\
\text { OPR } \\
\text { Prefix: t-o4 }\end{array}$ & $\begin{array}{l}\text { Name: Other Information on Major Operational Risk } \\
\text { Gross Losses } \\
\text { Prefix: m-om }\end{array}$ & $\begin{array}{l}\text { Name: Universal List } \\
\text { Prefix: d-ul }\end{array}$ \\
\hline $\begin{array}{l}\text { Name: OTH } 5 \\
\text { SEC } \\
\text { Prefix: t-o5 }\end{array}$ & $\begin{array}{l}\text { Name: Other Information on Securitisation Details } \\
\text { Prefix: m-sd }\end{array}$ & $\begin{array}{l}\text { Name: Universal List } \\
\text { Prefix: d-ul }\end{array}$ \\
\hline $\begin{array}{l}\text { Name: MKR SA } \\
\text { TDI } \\
\text { Prefix: t-td }\end{array}$ & $\begin{array}{l}\text { Name: Market Risk Standardised Approaches for Traded } \\
\text { Debt Instruments } \\
\text { Prefix: } m-t d\end{array}$ & $\begin{array}{l}\text { Name: Traded Debt } \\
\text { Instruments in Trading Book } \\
\text { Prefix: } \text { d-td }\end{array}$ \\
\hline $\begin{array}{l}\text { Name: MKR SA } \\
\text { EQU } \\
\text { Prefix: t-eb }\end{array}$ & $\begin{array}{l}\text { Name: Market Risk Standardised Approach for Equities } \\
\text { Prefix: m-eb }\end{array}$ & $\begin{array}{l}\text { Name: Equities in Trading } \\
\text { Book } \\
\text { Prefix: d-eb }\end{array}$ \\
\hline $\begin{array}{l}\text { Name: MKR SA } \\
\text { FX } \\
\text { Prefix: t-pr }\end{array}$ & $\begin{array}{l}\text { Name: MKR SA FX } \\
\text { Prefix: m-pr }\end{array}$ & $\begin{array}{l}\text { Name: Positions in Non- } \\
\text { Reporting Currencies } \\
\text { Prefix: d-pr }\end{array}$ \\
\hline
\end{tabular}

Chart 3 (Continued). Permitted Relationships. 


\begin{tabular}{|c|c|c|}
\hline $\begin{array}{l}\text { Name: MKR SA } \\
\text { COM } \\
\text { Prefix: t-pc } \\
\end{array}$ & $\begin{array}{l}\text { Name: Market Risk Standardised Approaches for } \\
\text { Commodities } \\
\text { Prefix: } \mathrm{m} \text {-pc }\end{array}$ & $\begin{array}{l}\text { Name: Positions in } \\
\text { Commodities } \\
\text { Prefix: } d-p c \\
\end{array}$ \\
\hline $\begin{array}{l}\text { Name: TB SA } \\
\text { SETT } \\
\text { Prefix: t-ut }\end{array}$ & $\begin{array}{l}\text { Name: Market Risk for Unsettled Transactions in the } \\
\text { Trading Book } \\
\text { Prefix: } m \text {-ut }\end{array}$ & $\begin{array}{l}\text { Name: Unsettled } \\
\text { Transactions in the Trading } \\
\text { Book } \\
\text { Prefix: d-ut }\end{array}$ \\
\hline
\end{tabular}

Chart 3 (Continued). Permitted Relationships.

As we can see, there are 32 measures, 20 dimensions, and from the table of permitted combinations, we are faced with a set of 31 templates.

The COREP templates are those shown in Chart 4:

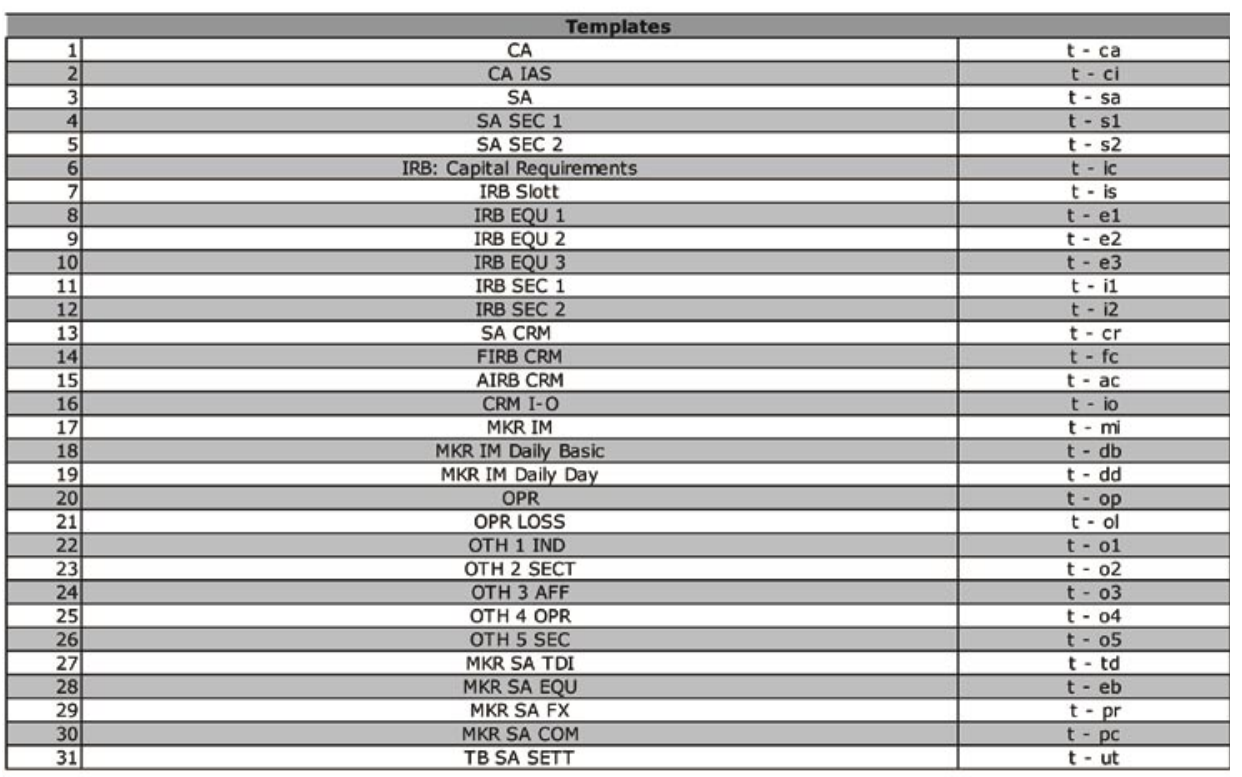

Chart 4. COREP Templates.

When several dimensions with one measure are indicated in a template, we only see one of those dimensions displayed, and the dimension not displayed takes only one of the values that, as a dimension, it can accommodate. In this way the fusion of more than two dimensions is achieved in a bidimensional table.

Overall, the model of matricial data that the COREP templates sustain is defined in the DataMatrix also available on www.corep.info, devised originally by Fréderic Marie (France) and Adrian Abbott (United Kingdom).

As can be seen in Chart 5, an example of the SA (Standard Approach) template, one of the dimensions is displayed (outlined by the oval), while the other two that 
appear in the same template, appear only enunciated (outlined by the circle), taking one of the values that they accommodate.

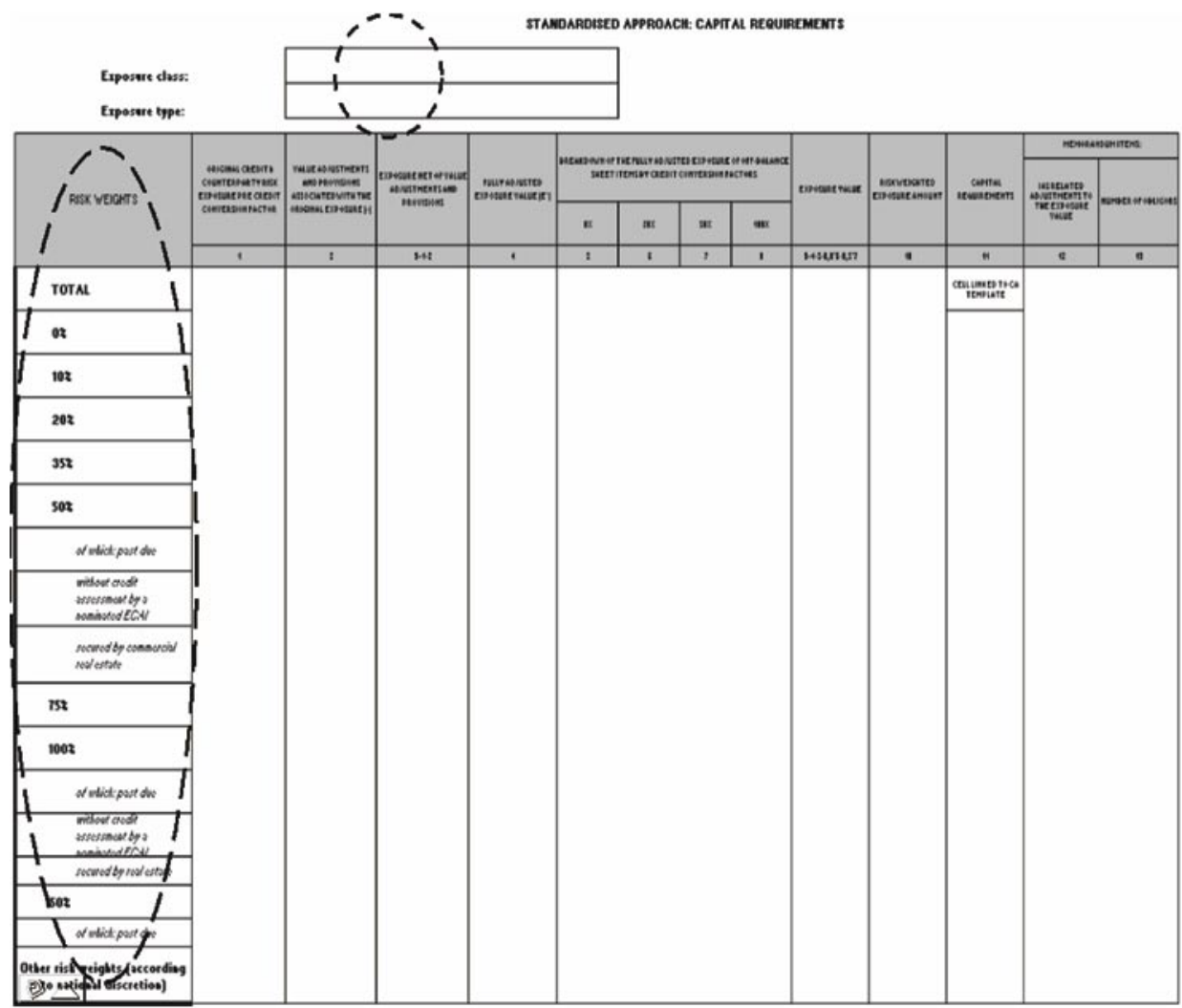

Chart 5 Example of the display of only one of the three dimensions present in respect of the measure.

Thus, the structure of measures, dimensions and templates has given rise to three groups of taxonomies, one for each element of the puzzle. Therefore there is a taxonomy for each measure, one for each dimension and one for each template. A template taxonomy imports the measure taxonomy and the dimension taxonomy or taxonomies that are required, in accordance with the chart of permitted relationships.

The principles proposed by the CEBS, on which the structure to be created is based, are:

$\checkmark$ Flexibility: the reporting model must allow each national supervisor to choose the degree of disaggregation that it may need in each case. It is better that this flexibility should take the form of each supervisor selecting 
from among the existing elements included in the taxonomies, rather than requiring new elements to be added.

$\checkmark$ Consistency: the model will make use of unequivocal terms with one single well-accepted meaning.

Standardisation: the number of templates to be created should be minimised.

In our opinion, both the model of templates proposed and the XBRL solution that supports it encompass and comply with these general principles.

The architecture of measures, dimensions and templates has required a modular scheme to be implemented, that is, each taxonomy is a file separate from the rest, to encourage future extensions and make the model comprehensible.

The existence of prohibited relationships and permitted relationships between measures and dimensions has been implemented principally through the use of Definition Linkbases. The method described here has been designed for this project, and is being reviewed and normalised by the International XBRL Consortium.

The DTS (discoverable taxonomy set) utilised has required the use of Definition Linkbases, in the following way:

$\checkmark$ The new arc role http://www.c-ebs.org/2005/arcrole/dimension-child defines the relationship between an abstract parent element and its children, which are the values of each dimension, in the dimension taxonomy.

$\checkmark$ he new arc role http://www.c-ebs.org/2005/arcrole/measure-child defines the relationship between an abstract parent element and its children, which are the values of each measure, in the measure taxonomy.

An abstract element designated DimensionPlaceHolder is created in the template taxonomy, which gives the name to a dimension. This permits a dimension to be utilised more than once in a template taxonomy. The relationship between the abstract parent element of the imported measure taxonomy and the DimensionPlaceHolder (parent-child relationship in this 
order), is orchestrated by means of the arc role: http://www.c-ebs.org/2005 arcrole/has-dimension

$\checkmark$ To delimit the valid values of the dimension, the child elements of the taxonomy of dimension are related to the DimensionPlaceHolder for which the arc role is used: http://www.xbrl.org/2003/arcrole/general-special

$\checkmark$ Lastly, to state that certain relationships between measures and dimensions are prohibited, the following arc role is used: http://www.c-ebs.org/2005 arcrole/dimension-not-allowed, placing the measure as parent and the dimension as child in this relationship.

With this procedure, the template taxonomy is structured.

To create instantiated XBRL documents, that is, XBRL reports, the procedure is as follows:

$\checkmark$ The creation of the XBRL report requires the use of the dimension-XXYY. xsd scheme.

$\checkmark$ The dimensions are expressed as references to elements of the dimension taxonomy/ies in the scenarios of the contexts. By way of example:

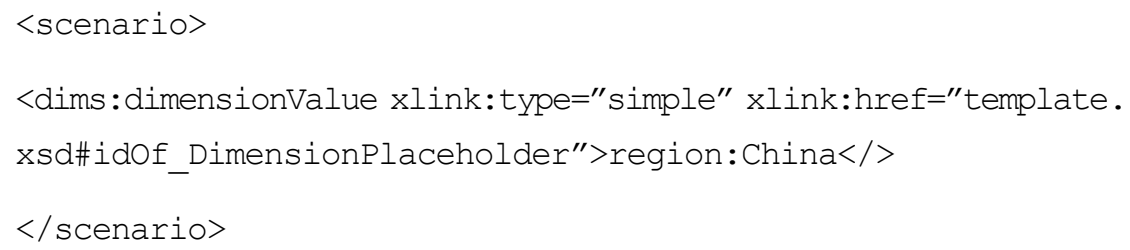

The COREP-XBRL taxonomy complies with and can be validated against the XBRL 2.1 Specification and against FRTA and FRIS. However, the dimensional structure needs the incorporation of the dimensional treatment into the XBRL specification for its correct validation. In any case, the explanatory document of the taxonomy includes mechanisms for validation against the specifications of the taxonomy itself.

We conclude this brief review by stating that, for a correct implementation of the taxonomy in banking entities and investment firms, the COREP group is developing 
different converters that allow the automatic creation of the corresponding XBRL reports, from files of diverse origin, using simple software tools.

\section{FINAL CONSIDERATIONS}

In Europe, everything presented in this paper is the objective of the COREP (COmmon REPorting) project, sponsored by the Committee of European Banking Supervisors (CEBS). The XBRL taxonomy that is going to help ensure an efficient implementation of the New Basel Capital Agreement has been developed in the COREP project.

The group, formed by experts and specialists from many different fields (banking supervision, computer systems, banking and investments, consultants, analysts, academics, ...), continues in operation at the present time, profiling and putting the finishing touches to the COREP-XBRL Taxonomy.

A review having been made of the documentation provided by the COREPXBRL working group on version 0.5 of the taxonomy for compliance with the New Basel Capital Agreement, some outstanding tasks remain:

$\checkmark$ To do a follow-up on the modifications that the collection of templates will undergo until the definitive approval by the European Parliament of the Reformed Directives (2000/12 and 93/6)

$\checkmark$ To do a follow-up on the detailed technical modifications that the taxonomy will undergo in subsequent versions, especially with the evolution foreseen in the XBRL standard for managing dimensions.

$\checkmark$ To study the possibility that the COREP-XBRL group might offer its services to the international community for the development of adequate extensions for the non-European areas, building on the international experience accumulated in the meetings of the group.

This document aims to demonstrate the disinterested effort of dozens of people who have worked hard over several months with one single goal: to develop the best tool for contributing to the development of the future European Financial Market. 
These developments in Europe can be extrapolated very easily to other countries. For the same reason that the requirements associated with the New Basel Capital Agreement, once expressed in terms of XBRL, are being adapted to the particular needs of any European country, this affirmation can also be safely made for any extra-European country, while reserving the exception of possible differences of legislative interpretation that might arise in relation to Directives 2000/12 and 93/6. What is needed is a collaborative atmosphere to strengthen and assure the compatibility between extensions of taxonomy, and especially that new elements should not be created for concepts already incorporated in the existing taxonomy (Silva and Ramos, 2004).

The multinational credit entities will obtain advantages if they can report to their national Supervisors using the same procedures and methods, independently of the country concerned, and even consolidate the individual reports for national supervision, to reflect their overall corporate situation. In this way a reduction of the total risk faced by the large credit corporations can be achieved. By presenting their solvency ratios in a homogeneous way in all the countries where they operate, the entities' various national reports to supervisors can be consolidated, in order to reinforce and facilitate the audit function confirming that the information issued does faithfully reflect their financial reality, thus strengthening the solidity of the entity as a whole, and that of the global financial system.(See fig.7).

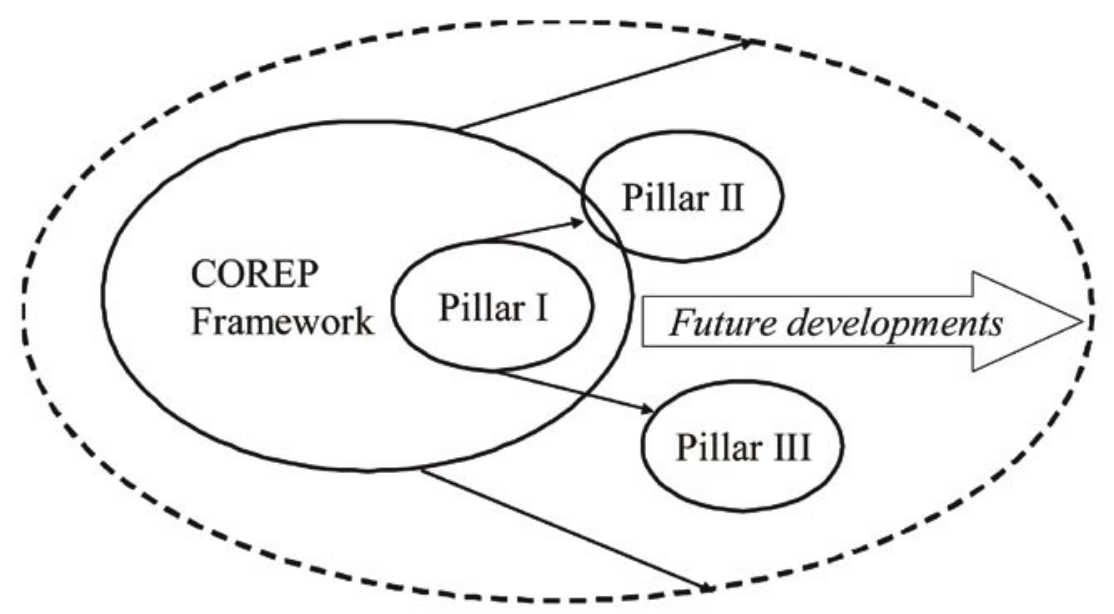

Figure 7. Future extra-European developments based on the COREP-XBRL model for Basel II. 
The development and the properties of XBRL would enable it to be applied to fiscal, notarial and other similar contexts. We can say that XBRL enables the rapid and easy preparation, issue and handling of diverse formal business information outputs by many kinds of entities (Hannon, 2002).

In the longer term future, no technological impediments exist for shortening the cycle of independent supervision. The desideratum in XBRL would be that the General Ledger may be a function that could be audited in real time. If the internal information of financial relevance of a company were expressed in XBRL, it would make it possible to initiate the auditing immediately after each financial fact had been reflected in the Ledger. The customary cycle of more than a year between the accounting of a fact and its auditing could, technically, be reduced most dramatically. The XBRL-GL taxonomy that makes this function possible has a different structure from the rest. Whereas other taxonomies incorporate concepts from certain reporting models, XBRL-GL must incorporate much, if not all, the basic information to provide the data stream that internal and external reporting demand (Garbellotto and Hannon, 2005). The extension of XBRL may encourage the use of data mining through repositories of files in this format (Prichard and Roodhani, 2004) which will allow a more complete analysis before taking investment decisions. An ever increasing range of dynamic references, measures and standards is being provided by the Real Time economy (Vasarhelyi et al., 2004), which should assist towards realising these objectives.

The COREP-XBRL Taxonomy is an example of how a collaborative and interdisciplinary international environment, combined with the clear intention of the authorities to promote homogenisation in respect of the laws and standards by which the markets are regulated, enable the creation of increasingly sophisticated, versatile, flexible and reliable tools for the exchange and treatment of business information.

\section{REFERENCES}

BONSÓN, E. (2001): “The role of XBRL in Europe”. The International Journal of Digital Accounting Research. Volume 1, Number 2, pp 101-110.

CODERRE, D. (2004): “Are you Ready for XBRL?" The Internal Auditor. Volume 61, No4, pp 26-29. 
COMMITTEE OF EUROPEAN BANKING SUPERVISORS (CEBS): http://www. c-ebs.org

COREP Working Group: http://www.corep.info

CRONIN, A; JAGGS, T. (2001): "An alternative Operational Risk Framework. OpRisk Partnership”. ClavisPoint Paper

EMBRECH, P., FURRER, H; KAUFMANN, R. (2004): "Quantifying regulatory capital for operational risk". ETH Zürich and London School of Economics.

GARBELlOTTO, G; HANNON, N. (2005): "Why XBRL Is a "Business" Reporting Language" Strategic Finance. Volume 86, Iss 11; pp 57-59.

HANNON, N. (2002): “Accounting scandals. Can XBRL help?" Strategic Finance. Volume 84, $\mathrm{N}^{\circ}$ 2, pp 61-63.

HODGE, F.D., KENNEDY, J.J; MAINES, L.A. (2004): “Does Search-Facilitating Technology Improve the Transparency of Financial Reporting?" The Accounting Review. Volume 79, № 3, pp 687-703.

MENDOVA, E.A; KYRIACOU, M.N. (2001): "Extremes in operational risk management" (working paper). Centre for Financial Research. University of Cambridge.

PEZIER, J. (2002): “Operational Risk Management" ISMA Centre Discussion Papers In Finance 2002-21.

PRICHARD, J.J; ROOHANI, S. (2004): "XBRL in practice: Developments of a Prototype Public File Repository for XBRL Documents: Challenges and Opportunities" The International Journal of Digital Accounting Research. Volume 4, No 7, pp 57-79.

ROWE, D., JOVIC, D; REEVES, R. (2004): "Bank Capital Management in the Light of Basel II". Journal of Performance Management. Atlanta. Tomo 17, $\mathrm{N}^{\circ} 1$, pp 15-26.

SILVA, A.C; RAMOS, M.B. (2004): "XBRL in practice: Reporting Standards for Statistical Purposes: The experience of Banco de Portugal" The International Journal of Digital Accounting Research. Volume 4, № 8, pp 145-174. 
VASARHELYI, M. A., ALLES M. G; KOGAN A. (2004) "Principles of Analytic Monitoring for Continuous Assurance". Journal of Emerging Technologies in Accounting. Volume 1, pp 1-21.

XBRL (2005): http://www.xbrl.org 